\title{
Sistem Informasi Inventarisasi Sumberdaya Perikanan Kabupaten Maluku Tenggara Dengan Metode Rapid Application Development
}

\author{
Lidya Elsye Reniban ${ }^{1}$ \\ ${ }^{1}$ Universitas Gunadarma Jakarta \\ e-mail: elsyereniban@gmail.com
}

\begin{abstract}
Southeast Moluccas Regency is a districts in Moluccas Province that is rich in marine fisheries resources, especially pelagic fish, seaweed, and demersal fish. Knowledge of information fisheries resources by fishermen and the community in general in the regions is still low, because the unavailability of easy information media to access information about fisheries resources in this area. The research aims to design an information system of fisheries resources inventory to improve the performance of the Southeast Moluccas Regency Government to inform and process data on fisheries resources. System design method uses RAD (Rapid Application Development). System design tools use UML (Unified Modeling Language), to make applications using the PHP(Hypertext Preprocessor) programming language, and MySQL as the database. Information System for Fisheries Resources has been tested using the blackbox method, the results show the system runs as expected. This system can display information on Southeast Moluccas Regency Fisheries Resources informally to the public and can be used as a tool for local governments to improve performance for presentation and processing of data and information in the marine and fisheries sector.
\end{abstract}

Keywords: Information Systems, Inventory, Fisheries, RAD, UML

\section{PENDAHULUAN}

Kabupaten Maluku Tenggara merupakan kabupaten kepulauan yang berada di Propinsi Maluku. Sebagaian masyarakatnya hidup di wilayah pesisir dan pulau - pulau kecil sehingga sebagian masyarakatnya adalah nelayan, maka kesejahteraan masyarakatnya juga tergantung dari sumberdaya perikanan yang terkandung di wilayah ini.

Wilayah pesisir merupakan kawasan yang paling produktif, karena menyediakan sumber daya alam yang langsung dan tidak langsung untuk dikonsumsi oleh masyarakat, sumber daya alam yang terkandung di wilayah pesisir terdiri dari sumber daya alam yang dapat pulih, yaitu sumber daya perikanan, rumput laut, padang lamun, dan lain sebagainya dan sumber daya alam yang tidak dapat pulih, yaitu minyak dan gas, pasir, timah, dan lain sebagainya (Dahuri et.al, 2008).

Perairan Maluku Tenggara pada umumnya perairan yang dangkal dan cukup kaya akan sumber daya hayati laut, khususnya ikan pelagis kecil, ikan pelagis besar, rumput laut, dan ikan demersal. Potensi sumberdaya perairan Maluku Tenggara cukup melimpah, sesuai Kepmen Kelautan dan Perikanan Republik Indonesia Nomor 47/KepmenKP/2016, Kabupaten Maluku Tenggara berada pada 2 wilayah pengelolaan perikanan (WPP) yakni : 1).
Wilayah pengelolaan perikanan - RI 714 meliputi Laut Banda dengan potensi sebesar 431,069 ton/tahun dengan Jumlah Tangkapan Yang Diperbolehkan (JTB) sebesar 344,856 ton/tahun. 2). Wilayah Pengelolaan Perikanan (WPP) - RI 718 meliputi Laut Arafura dengan potensi sebesar $1,992,730$ ton/tahun dengan jumlah tangkap yang diperbolehkan (JTB) sebesar 1,594,185 ton/tahun, terdiri dari ikan pelagis kecil, pelagis besar,ikan karang, ikan demersal dan non ikan. Jumlah produksi perikanan di Kabupaten Maluku Tenggara tahun 2016 adalah sebesar 171.531,85 ton dengan rincian, Produksi Sumber daya perikanan tangkap adalah sebesar 93.562,90 ton, produksi perikanan budidaya adalah sebesar 77.968,95 ton. Potensi sumber daya hayati perikanan tangkap yang dimaksud adalah ikan pelagis (selar, teri, kembung, tuna, tongkol, dll), demersial (kakap putih, kerapu, merah bambangan, dll), ikan karang serta sumberdaya perikanan budidaya adalah rumput laut, mutiara, kerapu (BPS Kab.Maluku Tenggara).

Potensi perikanan ini membutuhkan dukungan pengumpulan data yang lengkap agar dapat diinventarisir dan dikelola dengan baik dengan menggunakan teknologi informasi.

Pemanfaatan informasi sumberdaya perikanan memiliki manfaat yang beragam dan berbeda bagi pihak yang menggunakannya.masyarakat umum bisa memanfaatkannya sebagai informasi untuk 
mengetahui daerah potensial penangkapan ikan, kalangan bisnis bisa memanfaatkannya untuk memperolah data dan informasi guna menentukan prospek bisnis penangkapan dan industri perikanan, dan pemerintah dapat memanfaatkannya sebagai media untuk mendata potensi sumberdaya perikanan. Pengetahuan ketersediaan sumberdaya perikanan oleh masyarakat di daerah ini umumnya masih kurang, dikarenakan belum tersedianya media informasi yang memudahkan untuk mengakses informasi sumberdaya perikanan. Selain itu pemanfaatan teknologi informasi sebagai media pendukung belum dimanfaatkan secara optimal oleh Pemerintah Daerah lewat dinas Kelautan dan Perikanan Kabupaten Maluku Tenggara, karena data sumberdaya perikanan masih dikelola dengan menggunakan Microsoft Word dan Microsoft Excel, dan arsip dalam bentuk dokumen fisik, belum terkomputerisasi lewat sistem informasi manajemen yang lebih efisien dan efektif.

Penelitian sebelumnya yang merancang sistem informasi perikanan berbasis online adalah berjudul "Desain Sistem Informasi Perikanan Pole and Line Berbasis Online Di Perairan Teluk Bone”. Tujuan penelitian adalah mendesain sistem informasi perikanan pole and line berbasis online di perairan Teluk Bone sesuai dengan kebutuhan stakeholders. Sistem informasi perikanan pole and line bermanfaat untuk membantu stakeholder untuk mengakses informasi dengan mudah dan relevan dalam kebutuhan perikanan pole and line (Rachmat Hidayat , dkk, 2016 ). Penelitian diatas memiliki konsep yang sama dengan penelitian ini yaitu memanfaatan teknologi informasi berbasis web yang bertujuan membantu kinerja instansi atau pemerintah daerah setempat untuk mengolah data dan menampilkan informasi dibidang perikanan yang mudah diakses secara cepat dan akurat.

Berdasarkan uraian diatas permasalahan yang timbul adalah bagaimana mengolah data sumberdaya perikanan di Kabupaten Maluku Tenggara dengan menggunakan teknologi informasi sehingga dapat menampilkannya secara informatif. Tujuan penelitian ini adalah merancang sistem informasi dan pengolahan data sumberdaya perikanan berbasis web agar mudah diakses secara cepat dan akurat guna meningkatkan kinerja Pemerintah Daerah lewat dinat terkait untuk menginformasikan sumberdaya perikanan daerah ini.

\section{METODE PENELITIAN}

Metodologi yang digunakan untuk merancang aplikasi sistem informasi inventarisasi sumberdaya perikanan ini yaitu dengan tahapan sebagai berikut.

\section{Teknik Pengumpulan Data}

Untuk memperoleh data yang sesuai dengan tujuan dari penelitian ini, maka penulis menggunakan teknik pengumpulan data sebagai berikut : a) Data primer, dengan melakukan teknik wawancara personal, yaitu melakukan tatap muka langsung dengan responden. Tujuan wawancara ini adalah untuk memperoleh data dan informasi tentang perkembangan dan pemanfaatan teknologi informasi yang dimanfaatkan di Dinas Kelautan dan Perikanan Kabupaten Maluku Tenggara serta kendala kendala yang dihadapi dalam memanfaatkan teknologi informasi. Teknik pengambilan data observasi non-perilaku, yaitu observasi analisis catatan yang bertujuan untuk mengumpulkan data untuk kebutuhan perancangan sistem aplikasi, dan observasi analisis proses fisik yang bertujuan untuk mengamati proses dari sistem informasi inventarisasi perikanan yang sekarang sedang digunakan.

b) Data sekunder, diperoleh dengan melakukan teknik studi literatur, bertujuan untuk memperoleh ilmu pengetahuan tentang teori dan penelitian - penelitian yang sejenis yang membantu penulis untuk merancang sistem informasi inventarisasi sumberdaya kelautan dan perikanan berbasis web.

\section{Metode Perancangan Sistem}

Perancangan sistem pada penelitian ini menggunakan metode Rapid Application Develepment (RAD).

Tahapan metode Rapid Aplication Development $(R A D)$ dalam penelitan ini sebagai berikut:

a) Rencana Kebutuhan (Requirements phase), proses ini untuk mengidentifikasi tujuan dari aplikasi yang akan dibangun, mengidentifikasi kebutuhan dari sistem yang akan dibangun, serta menentukan teknik atau pendekatan yang akan digunakan untuk membangun sistem.

b) Desain sistem, proses yang dilakukan yaitu perancangan proses - proses yang akan berjalan pada sistem, perancangan database dan perancangan antar muka, sekaligus melakukan perbaikan - perbaikan jika terjadi ketidaksesuaian dengan pengguna.

c) Implementasi/coding, tahapan implemetasi merupakan tahapan sistem dirancang secara fisik dengan melibatkan sistem komputer berdasar hasil rancangan, jika proses coding telah selesai atau sedang berjalan maka dilakukan pengujian (testing) yang bertujuan mengetahui apakah sistem sudah bebas dari kesalahan, jika terdapat kesalahan maka dilakukan perbaikan.

d) Pengujian, tahapan ini dilakukan jika semua tahapan dalam proses perancangan sistem telah selesai dilakukan. Pengujian dilakukan untuk mengetahui apakah sistem berjalan sesuai yang diharapkan atau tidak. 


\section{HASIL DAN PEMBAHASAN}

Tahapan perancangan sistem informasi inventarisasi sumberdaya perikanan ini menerapkan tahapan tahapan pada $R A D$ yang dijelaskan secara detail sebagai berikut.

\section{Rencana Kebutuhan Sistem}

Proses yang dilakukan pada fase ini adalah mengidentifikasikan tujuan dan kebutuhan sistem yang akan dibangun, menentukan teknik atau pendekatan yang digunakan

\subsection{Identifikasi Tujuan}

Pada tahapan ini analis melakukan wawancara dan observasi di Dinas Keluatan dan Perikanan Kab. Maluku Tenggara, dengan data dan informasi yang didapatkan analis melakukan analisis sistem sebelumnya yang sedang berjalan didapati bahwa pengolahan dan penyimpanan data sumberdaya perikanan Kabupaten Maluku Tenggara melalui Dinas Kelautan dan Perikanan saat ini telah menggunakan media komputer dengan memanfaatkan aplikasi Microsoft Word dan Microsoft Excel, selain itu sebagian data juga tersimpan dalam bentuk arsip/dokumen fisik, sehingga untuk mencari dan melakukan modifikasi data membutuhkan waktu yang lama, sehingga keefektifan serta keakuratan data tidak terjamin. Masalah - masalah diatas timbul karena beberapa kendala yaitu: Dinas Kelautan dan Periknan Kab.Maluku Tenggara belum memiliki sistem informasi yang terkomputerisasi untuk menginventarisir semua data hingga mudah diakses. Data - data tidak terorganisir dengan baik, sebagian data tersimpan dalam file dikompter dan sebagian dalam bentuk arsip dokumen fisik. Belum memiliki sistem manajemen database untuk mengelola data dan informasi secara komprehensif.

Berdasarkan kendala dan masalah diatas maka tujuan dari sistem baru yang ditawarkan yaitu merancang aplikasi sistem informasi inventarisasi data sumberdaya perikanan berbasis web, sistem ini akan membantu Dinas Keluatan dan Perikanan Kab. Maluku tenggara untuk mengolah data sumberdaya perikanan melalui sistem database dan menampilkan informasi sumberdaya perikanan yang informatif dalam bentuk dokumen, tabel, diagram, dan laporan yang dicetak, secara cepat,tepat, mudah, dan akurat berbasis web.

1.2.

Analisis Kebutuhan Sistem

Setelah melalui proses indentifikasi awal, analis kemudian melakukan analisis untuk mengidentifikasikan kebutuhan dari sistem baru yang akan dibangun. Analisis kebutuhan sistem terdiri atas kebutuhan fungsional dan kebutuhan non fungsional. Analisis Kebutuhan fungsional bertujuan untuk menganalisis dan menggambarkan fungsi dari setiap proses proses dari sistem informasi yang dibangun. Adapun kebutuhan fungsional dari sistem ini adalah

a) Sistem menyajikan informasi sumberdaya ikan setiap kecamatan, deskripsi ikan dan jumlah produksi ikan pertahun sesuai dengan jenisnya

b) Sistem menyajikan informasi sumberdaya perikanan tangkap (alat tangkap, armada penangkapan, nelayan), dekripsi perikanan tangkap, dan jumlahnya disetiap kecamatan per tahun, menghitung estimasi jumlah penangkapan ikan berdasarkan jenis alat tangkap per tahun.

c) Sistem menyajikan informasi sumberdaya perikanan budidaya (lahan budidaya dan hasil budidaya), deskripsi perikanan budidaya, jenis lahan budidaya setiap kecamatan, menampilkan desa potensial yang memiliki lahan budidaya dan peruntukannya dari setiap kecamatan.

d) Sistem menyajikan informasi hasil budidaya ikan dan non ikan, jumlah produksi budidaya non ikan pertahun,

e) Sistem menyajikan informasi jenis sumberdaya ekosistem laut setiap kecamatan.

f) Pengunjung dapat memasukan saran dan ditampilkan dihalaman web

g) Admin dapat login ke halaman web admin

h) Sistem dapat menambah, mengubah, dan menghapus data sumberdaya perikanan yang dilakukan oleh admin dihalaman web admin

i) Pengunjung dapat mencetak data dan informasi yang disediakan oleh sistem.

Kebutuhan non fungsional bertujuan untuk menganalisis kebutuhan - kebutuhan apa saja yang menunjang proses sistem ini agar berjalan sesuai yang diharapkan. Yang termasuk kebutuhan non fungsional adalah ,kebutuhan pengguna, dan kebutuhan data.

Kebutuhan Pengguna Sistem yang menggunakan sistem ini adalah Admin dan Pengunjung aplikasi. Admin adalah bagian pengguna aplikasi yang memiliki hak akses lebih banyak untuk mengoperasikan aplikasi daripada para pengguna lainnya demi keamanan sistem. Admin dapat melihat tampilan website dan mengelola data sumberdaya perikanan di halaman web admin yaitu menambah, mengubah, dan menghapus. Admin harus memiliki kemampuan dasar untuk mengoperasikan komputer dan kemampuan dasar mengelola database dengan $M y S Q L$. Pengunjung aplikasi, adalah pengguna aplikasi yang memiliki hak akses terbatas, yaitu hanya melihat tampilan 
website pengunjung, mencetak laporan yang disediakan, dan memasukan saran.

Kebutuhana data, data yang dibutuhkan untuk membangun sistem adalah data sumberdaya ikan, data sumberdaya perikanan budidaya, data sumberdaya perikanan tangkap, data produksi ikan dan non ikan, data sumberdaya ekosistem laut dan pesisir

\section{Proses Desain}

Proses yang dikerjakan pada fase ini adalah perancangan proses sistem yang baru dengan menggunakan alat bantu pemodelan sistem, perancangan database, dan perancangan antarmuka.

\subsection{Model Perancangan Sistem}

Alat bantu pemodelan yang dipakai untuk merancang Sistem ini adalah UML (Unified Modelling Language) yaitu dengan menggunakan Use Case Diagram dan Activity Diagram. Pemakaian UML (Unified Modelling Language) sebagai alat bantu perancangan sistem bertujuan secara visual menjelaskan dan memberikan spesifikasi proses bisnis yang terjadi pada sistem.

Use Case Diagram menggambarkan fungsi dari sistem yang akan dibangun. Use case diagram sistem informasi inventarisasi perikanan ini menunjukan proses interaksi antara 2 actor dengan sistem yang dibangun yaitu admin dan pengunjung web. Secara terperinci dapat dilihat pada gambar.1 dibawah ini.

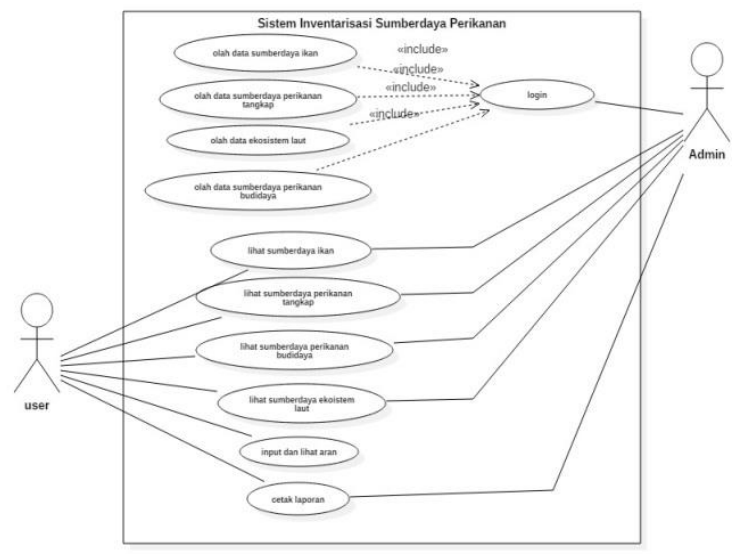

Sumber : Hasil Penelitian (2018)

Gambar.1. Use Case Diagram Sistem Inventarisasi Sumberdaya Perikanan

Dari Gambar.1 diatas proses yang dilakukan dan menjadi tanggungjawab Admin adalah proses login mengelola data sumberdaya ikan, mengolah data sumberdaya perikanan tangkap, mengolah data sumberdaya perikanan budidaya, dan mengolah data ekosistem laut. Pengelolaan data yang dilakukan adalah menambahkan data, mengubah data, dan menghapus data. Pengunjung web, proses yang dilakukan adalah melihat informasi sumberdaya ikan, sumberdaya perikanan tangkap, sumberdaya perikanan budidaya, sumberdaya ekosistem laut, memasukan saran dan melihat saran, mencetak laporan.

Activity Diagram yang digunakan untuk perancangan sistem ini bertujuan untuk menggambarkan berbagai alir aktivitas dalam sistem , bagaimana masing - masing alir berawal, decision yang mungkin terjadi, dan bagaimana masing - masing alir berakhir. Activity Diagram Sistem informasi inventarisasi sumberdaya perikanan menunjukan activity diagram proses menambah data ikan yang dilakukan oleh admin pada halaman web admin.

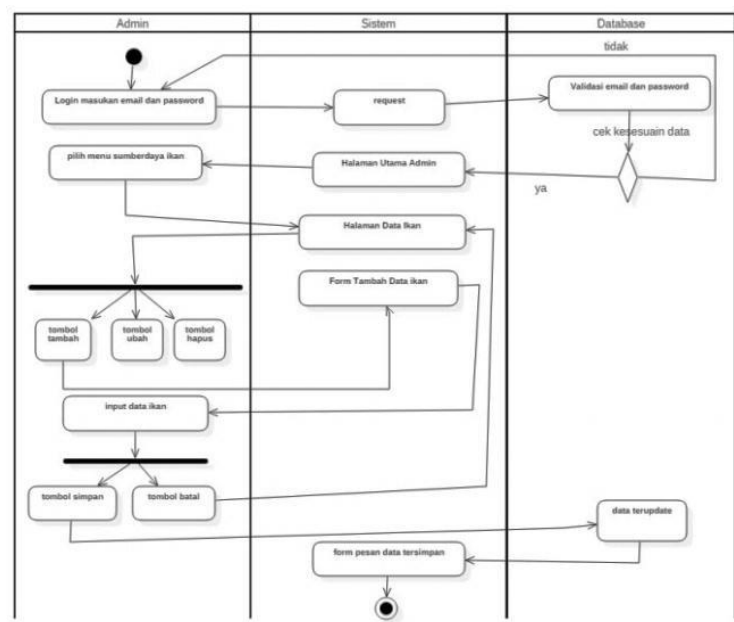

Sumber : Hasil Penelitian (2018)

Gambar.2. Activity Diagram Menambah Data Ikan

Dari Gambar.2 diuraikan tahapan- tahapan yang dilakukan oleh admin untuk menambah data ikan, pertama untuk masuk ke halaman web admin, admin mengakses form login lalu input email dan password, sistem melakukan validasi data di database, jika tidak sesuai maka kembali ke form login, dan jika sesuai maka sistem akan menampilkan halaman utama admin sistem informasi inventarisasi perikanan. Admin memilih menu sumberdaya ikan, sistem akan menampilkan halaman tampilan data ikan. Admin memilih tombol tambah data, sistem akan menampilkan form tambah data ikan, setelah data dimasukan, jika menekan tombol batal maka data tidak tersimpan didatabase dan kembali ke halaman data ikan, jika menekan tombol simpan maka data akan terupdate dan tersimpan didatabase, dan sistem akan menampilkan form pesan data telah tersimpan, aktifitas menambah data selesai. 


\subsection{Perancangan Database}

Database merupakan komponen penting sebagai tempat untuk menyimpan data yang terstruktur, agar mudah dan cepat diakses. Pemodelan basis data sistem informasi inventarisasi sumberdaya perikanan ini dilakukan dengan menggunakan Entity Relationship Diagram (ERD) .Tahapan yang dilakukan untuk perancangan database adalah pertama menentukan entitas (obyekobyek utama dalam database) dan atributenya, kemudian menentukan relationalship dari setiap entitas kemudian membuat Entity Relationship Diagram (ERD), seperti terlihat pada Gambar.3 berikut.

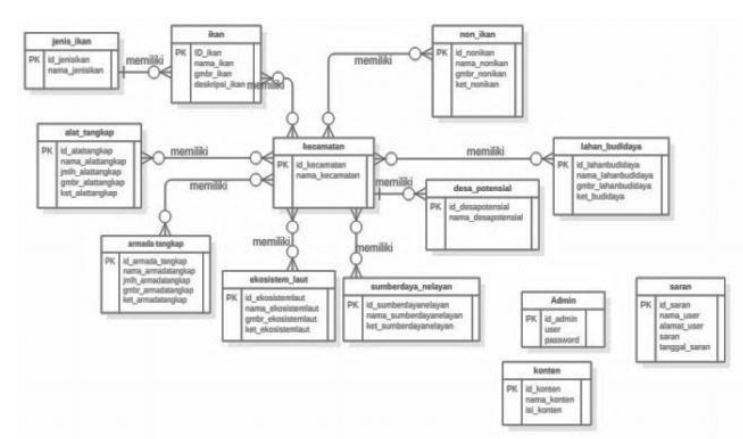

Sumber : Hasil Penelitian (2018)

Gambar.3. Entity Relationship Diagram (ERD) Sistem Informasi Inventarisasi Sumberdaya Perikanan

\subsection{Perancangan Antar Muka}

Perancangan antar muka merupakan desain utama untuk membuat user interface dari sistem yang dibangun sesuai dengan model perancangan sistem pada tahapan desain sistem. Rancangan antar muka bertujuan untuk menampilkan data yang telah di-input kemudian diproses menjadi tampilan output yang informatif. Perancangan antarmuka terdiri atas dua yaitu halaman frontend bagi pengunjung website dan halaman backend bagi admin di website admin.
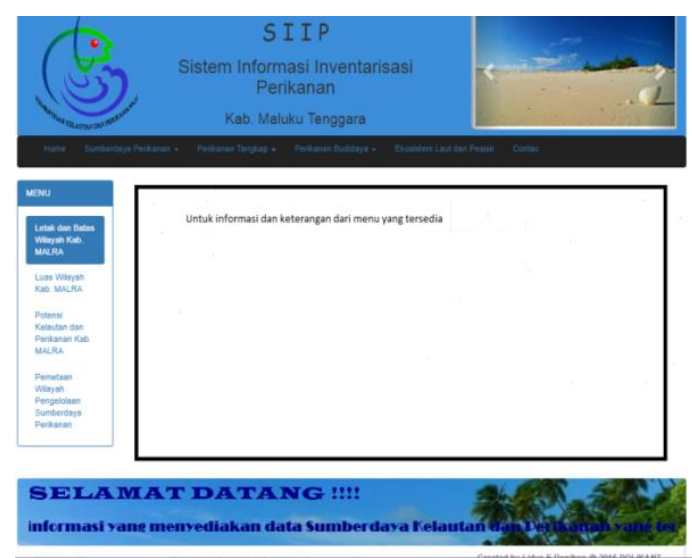

Sumber : Hasil Penelitian (2018)

Gambar.4.Rancangan Halaman Utama Frontend
Halaman frontend terdapat berbagai tombol menu yang disediakan bagi pengunjung website untuk memperoleh informasi yang diinginkan, yang ditunjukan pada Gambar.4. Sedangkan Halaman backend pada Gambar.5 untuk admin juga terdapat berbagai tombol menu yang disediakan untuk melakukan layanan modifikasi data agar hasilnya dapat ditampilkan dihalaman website pengguna.

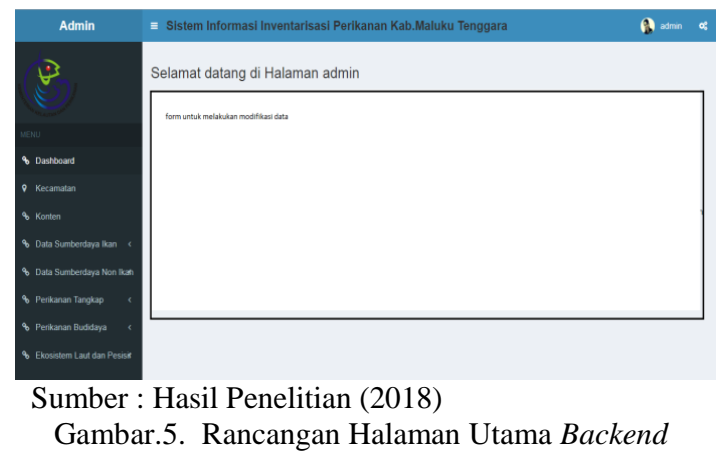

\section{Implementasi}

Lingkup implemetasi yang akan dipaparkan secara detail setelah tahapan design sistem adalah implementasi database dan implementasi antar muka

\subsection{Implementasi Database}

Implematsi database sistem informasi inventarisasi sumberdaya perikanan Kab. Maluku Tenggara, menggunakan aplikasi MySQL. Langkah awal membuat database untuk sistem ini dengan membuat database dengan nama "si" di aplikasi MySQL. Database "si" terdiri atas tabel- tabel untuk menyimpan data perikanan, sebagai contoh struktur tabel ikan yang dibuat di aplikasi MySQL seperti Gambar.6.

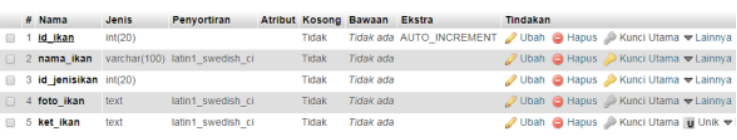

Sumber : Hasil Penelitian (2018)

Gambar.6. Struktur Tabel Ikan

\subsection{Implementasi Antar Muka}

Implementasi antar muka merupakan hasil akhir dari semua rangkaian perancangan sistem pada tahap sebelumnya yang menghasilkan aplikasi Sistem Informasi Inventarisasi Sumberdaya Perikanan Kab.Maluku Tenggara. Untuk membangun aplikasi sistem ini menggunakan aplikasi bahasa pemograman PHP (Hypertext Preprocessor) .

a) Halaman website admin

Sebelum Admin masuk kehalaman utama website admin, harus lakukan login terlebih dahulu dengan memasukan email dan password, seperti pada Gambar.8 dibawah. 
Data email dan password admin telah diinput sebelumnya di database tabel admin. Jika data login sesuai dengan database maka admin dapat masuk ke halaman website admin.

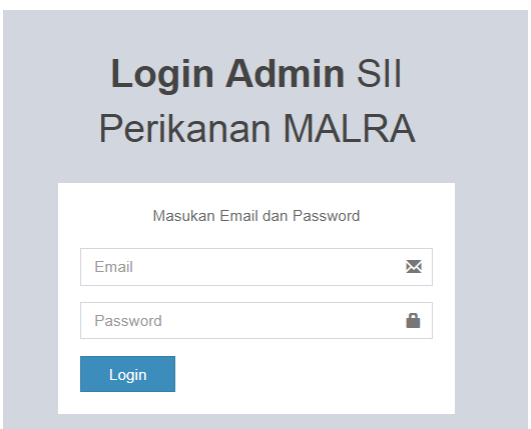

Sumber : Hasil Penelitian (2018)

Gambar.7.Form Login Admin

Halaman utama admin pada Gambar.8 terdapat pilihan menu - menu yang disediakan untuk modifikasi data sumberdaya kelautan dan perikanan disisi kiri tampilan website, bagian tengah tampilan website terdapat penjelasan fungsi dari setiap menu, dan sisi kanan atas website terdapat tombol admin untuk logout dari website admin.

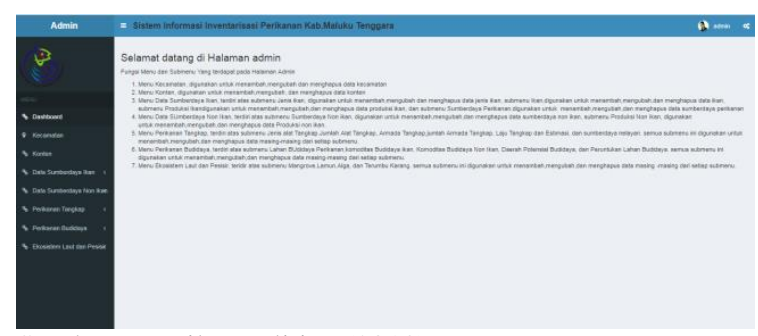

Sumber : Hasil Penelitian (2018)

Gambar.8. Halaman Utama Admin

Untuk melihat informasi ikan admin dapat memilih menu ikan pada Data Sumberdaya Ikan, menu ini berisikan data dan informasi tentang sumberdaya ikan yang telah di input sebelumnya, seperti Gambar.9 dibawah.

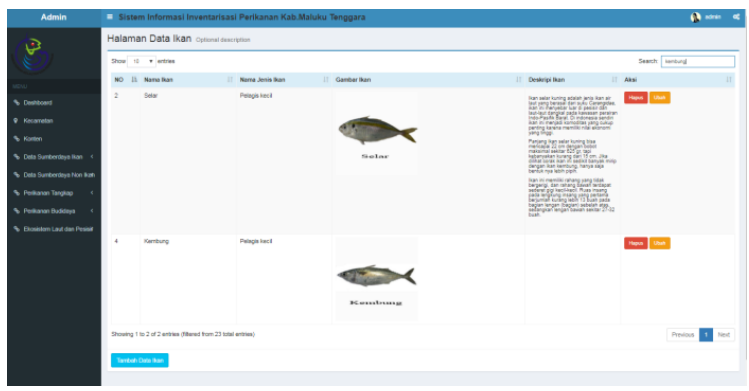

Sumber : Hasil Penelitian (2018)

Gambar.9.Halaman Data Ikan

Halaman data ikan terdapat informasi ikan yang berdasarkan jenis, nama, gambar, dan deskripsi ikan. Sisi kanan terdapat tombol Ubah dan Hapus data untuk ikan yang dipilih, sedangkan untuk menambah data ikan terdapat tombol Tambah disisi kiri bawah. Form untuk menambah data ikan terlihat seperti Gambar.10 berikut.

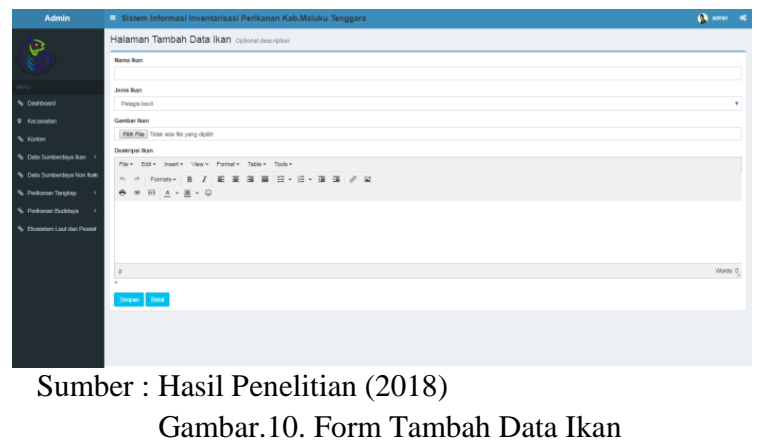

Selain menambah data ikan admin juga dapat mengubah, menghapus data ikan, seperti pada Gambar.11 adalah form untuk mengubah data ikan.

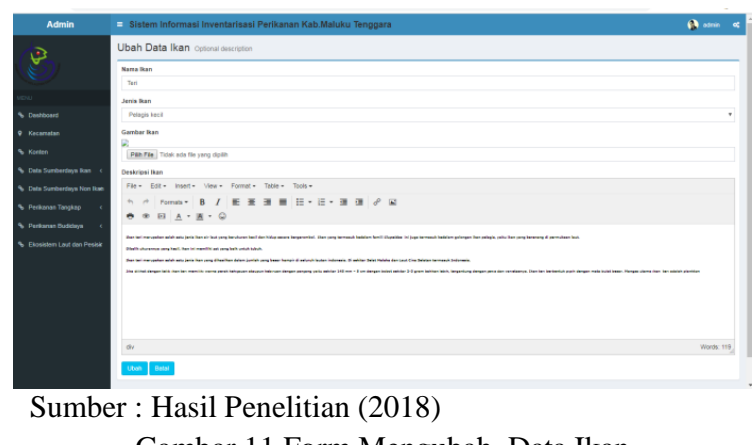

Gambar.11.Form Mengubah Data Ikan

Untuk menghapus data ikan admin memilih tombol Hapus pada data ikan yang hendak dihapus, dan sistem akan menampilkan pesan konfirmasi, terlihat pada gambar.12. Jika admin memilih Oke maka data ikan yang dipilih akan terhapus dari database.

localhost menyatakan

Yakin akan menghapus?

Sumber : Hasil Penelitian (2018)

Gambar.12. Konfirmasi Hapus Data

Semua data yang dimodifikasi oleh admin dihalaman backend tersimpan pada database.

b) Halaman website pengunjung

Untuk masuk kehalaman website pengujung memasukan alamat website sistem aplikasi lewat address bar browser dan sistem akan 
menampilkan halaman utama website, seperti Gambar.13.

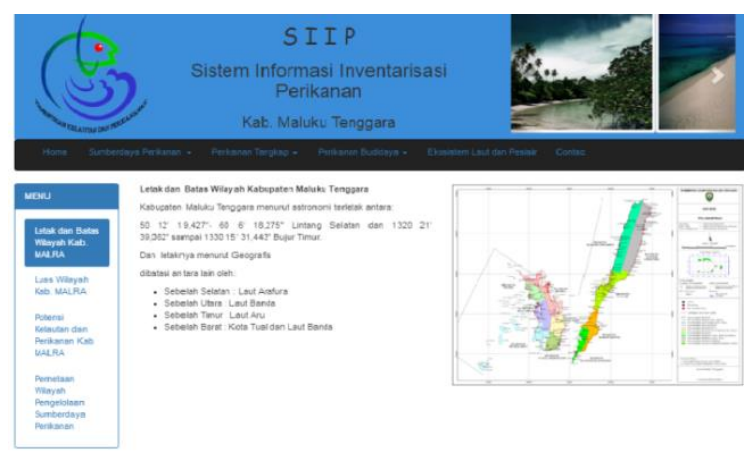

Sumber : Hasil Penelitian (2018)

Gambar.13. Halaman Utama Pengunjung

Website pengunjung bertujuan untuk menampilkan informasi tentang sumberdaya kelautan dan perikanan yang dimiliki oleh Kab. Maluku Tenggara. Pengujung website bisa mendapatkan kebutuhan informasi dengan pilihan menu - menu pada website, yaitu informasi sumberdaya ikan, sumberdata perikanan tangkap, sumberdaya perikanan budidaya, dan sumberdaya ekosistem laut dan pesisir.

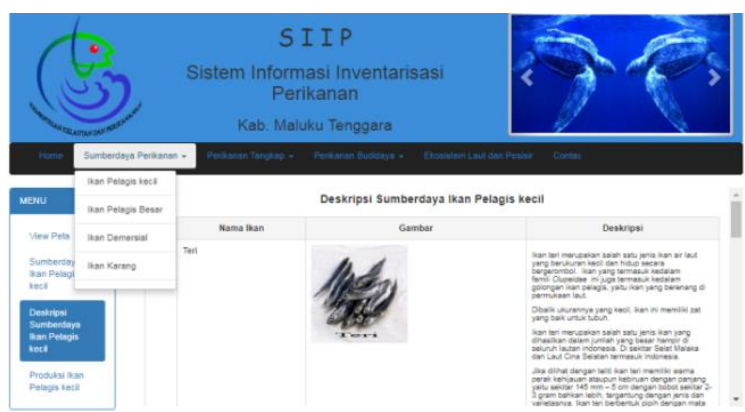

Sumber : Hasil Penelitian (2018)

Gambar.14.Menu Sumberdaya Perikanan Ikan Pelagis Kecil

Gambar.14, merupakan salah satu tampilan menu pada website pengunjung yaitu Menu sumberdaya perikanan untuk jenis ikan pelagis kecil. Menu sumberdaya perikanan ikan pelagis kecil akan menyajikan informasi untuk melihat peta sebaran ikan pelagis kecil sesuai pengukuran lapangan, jenis ikan pelagis kecil yang terdapat disetiap kecamatan, deskripsi ikan pelagis kecil yang terdapat di Kab. Maluku Tenggara, dan laporan jumlah produksi ikan pelagis kecil pertahun dalam bentuk tabel dan grafik yang bisa dicetak oleh pengunjung.

\section{Pengujian}

Tahapan pengujian dilakukan setelah tahapan implementasi selesai dikerjakan. Pengujian dilakukan dengan menjalankan semua fungsi dan fitur yang terdapat pada sistem aplikasi, dengan mengamati aktifitas input, proses, dan output. Aplikasi sistem informasi inventarisasi sumberdaya perikanan diuji dengan menggunakan metode blackbox testing yang ditunjukan pada Tabel.1.

Metode Blackbox Testing merupakan salah satu metode yang mudah digunakan karena hanya memerlukan batas bawah dan batas atas dari data yang di harapkan (Mustaqbal,dkk,2015). Metode Blackbox Testing yang dilakukan bertujuan untuk mengetahui apakah sistem aplikasi yang dibangun hasilnya sesuai dengan yang diharapkan atau tidak.

Tabel.1. Hasil Pengujian dengan Blackbox Testing

\begin{tabular}{|c|c|c|c|}
\hline No & Test Case & $\begin{array}{l}\text { Hasil yang } \\
\text { diharapkan }\end{array}$ & Hasil \\
\hline 1 & $\begin{array}{l}\text { Splash screen } \\
\text { browser halaman } \\
\text { pengunjung }\end{array}$ & $\begin{array}{l}\text { Menampilkan } \\
\text { Halaman Utama } \\
\text { (Home) Dari Aplikasi }\end{array}$ & Sesuai \\
\hline 2 & $\begin{array}{l}\text { Menu Ikan } \\
\text { Pelagis Kecil }\end{array}$ & $\begin{array}{l}\text { Menampilkan } \\
\text { Informasi Tentang } \\
\text { Ikan Pelagis Kecil }\end{array}$ & Sesuai \\
\hline 3 & $\begin{array}{l}\text { Menu Ikan } \\
\text { Pelagis Besar }\end{array}$ & $\begin{array}{l}\text { Menampilkan } \\
\text { Informasi Tentang } \\
\text { Ikan Pelagis Besar }\end{array}$ & Sesuai \\
\hline 4 & $\begin{array}{l}\text { Menu Ikan } \\
\text { Demersial }\end{array}$ & $\begin{array}{l}\text { Menampilkan } \\
\text { Informasi Tentang } \\
\text { Ikan Demersial }\end{array}$ & Sesuai \\
\hline 5 & $\begin{array}{l}\text { Menu Ikan } \\
\text { Karang }\end{array}$ & $\begin{array}{l}\text { Menampilkan } \\
\text { Informasi Tentang } \\
\text { Ikan Karang }\end{array}$ & Sesuai \\
\hline 6 & $\begin{array}{l}\text { Menu Jenis Alat } \\
\text { Tangkap }\end{array}$ & $\begin{array}{l}\text { Menampilkan } \\
\text { Informasi Tentang } \\
\text { jenis alat tangkap }\end{array}$ & Sesuai \\
\hline 7 & $\begin{array}{l}\text { Menu Armada } \\
\text { Penangkapan }\end{array}$ & $\begin{array}{l}\text { Menampilkan } \\
\text { Informasi Armada } \\
\text { Penangkapan }\end{array}$ & Sesuai \\
\hline 8 & $\begin{array}{l}\text { Menu } \\
\text { Sumberdaya } \\
\text { Nelayan }\end{array}$ & $\begin{array}{l}\text { Menampilan } \\
\text { Informasi } \\
\text { Sumberdaya Nelayan }\end{array}$ & Sesuai \\
\hline 9 & $\begin{array}{l}\text { Menu Potensi } \\
\text { Lahan Budidaya }\end{array}$ & $\begin{array}{l}\text { Menampilkan } \\
\text { Informasi Potensi } \\
\text { Lahan Budidaya }\end{array}$ & Sesuai \\
\hline 10 & $\begin{array}{l}\text { Menu Potensi } \\
\text { Hasil Budidaya } \\
\text { Laut }\end{array}$ & $\begin{array}{l}\text { Menampilkan } \\
\text { Informasi Hasil } \\
\text { Budidaya Laut }\end{array}$ & Sesuai \\
\hline 11 & $\begin{array}{l}\text { Menu Ekosistem } \\
\text { Laut dan Pesisir }\end{array}$ & $\begin{array}{l}\text { Menampilkan } \\
\text { Informasi ekosistem } \\
\text { laut dan pesisir }\end{array}$ & Sesuai \\
\hline
\end{tabular}




\begin{tabular}{|c|c|c|c|}
\hline 12 & $\begin{array}{l}\text { Menu Saran dan } \\
\text { kontak }\end{array}$ & $\begin{array}{l}\text { Menampilkan } \\
\text { informasi kontak dan } \\
\text { saran dari } \\
\text { pengunjung }\end{array}$ & Sesuai \\
\hline 13 & Cetak laporan & $\begin{array}{l}\text { Laporan yang dicetak } \\
\text { di-download dan } \\
\text { tersimpan pada } \\
\text { personal } \\
\text { computer }(P C) \\
\text { pengunjung dalam } \\
\text { bentuk file MS.Excel. }\end{array}$ & Sesuai \\
\hline
\end{tabular}

Sumber : Hasil Penelitian (2018)

\section{KESIMPULAN}

\section{Simpulan}

Dari penelitian yang dipaparkan diatas dapat ditarik beberapa kesimpulan sebagai berikut
a) Aplikasi Sistem Informasi Inventarisasi Perikanan ini dapat memberikan informasi kepada masyarakat tentang Potensi Sumberdaya Kelautan dan Perikanan di Kab. Maluku Tenggara.

b) Aplikasi Sistem Informasi Inventarisasi ini dapat dijadikan alat bantu pengolahan data perikanan di Dinas Kelautan dan Perikanan Kabupaten Maluku Tenggara karena sistem dapat menyimpan data kedalam database sehingga data bisa diperbaharui dan diakses dengan cepat dan akurat.

\section{Saran}

a) Aplikasi Sistem Informasi Inventarisasi Sumberdaya Perikanan Kab. Maluku Tenggara Berbasis Web, masih terbatas pada Bidang Sumberdaya Ikan, Perikanan Tangkap dan Perikanan Budidaya , diharapkan kedepannya dapat dilakukan pengembangan untuk data dan informasi dibidang Teknologi Hasil Perikanan, Agribisnis Perikanan, dan Agrowisata Perikanan.

b) Peta yang terdapat pada Aplikasi ini masih terbatas pada peta sebaran sumberdaya ikan. Diharapkan dalam pengembangan kedepan dapat dikembangkan untuk dibidang perikanan yang lain yaitu perikanan tangkap dan perikanan budidaya guna penyajian informasi yang lebih informatif dalam bentuk peta.

\section{REFERENSI}

AL-BAHRAN,2013, Analisis dan Desain Sistem Informasi, Graha Ilmu Yogyakarta.

BADAN PUSAT STATISTIK, Maluku Tenggara dalam angka 2017 [online] available at https://malukutenggarakab.bps.go.id (accessed 25 september 2018).
DAHURI ET.AL, 2008, Pengelolaan Sumber Daya Wilayah Pesisir dan Laut secara terpadu, Pradnya Paramitha Jakarta.

HIDAYAT.R. ， ZAINUDDIN.M SELAMAT.M.B., 2016. Desain Sistem Informasi Perikanan Pole And Line Berbasis Online Di Perairan Teluk Bone. Jurnal IPTEKS PSP, Vol.3,No.6: 484 - 500.

JODI.M, TANAAMAH.A.R,2017. Perancangan Dan Implementasi Sistem Informasi Penjualan Berbasis Desktop Website Menggunakan Framework Bootstrap Dengan Metode Rapid Application Development, Studi Kasus Toko Peralatan Bayi 'Eeng Baby Shop'. Jurnal Teknologi Informasi dan Ilmu Komputer,Vol.5,No.1:57-68

JUAINI, MAULANA ASHARI,2018. Sistem Informasi Pengolahan Data Inventaris Dan Pengdaan Barang Pada Kantor Desa Lenting Berbasis Web. Jurnal Manajemen Informatika \& Sistem Informasi.Vol.1,No.2:49-54

KENDALL , 2010. Analisis dan Perancangan Sistem, edisi kelima, Indeks Jakarta.

KEPMEN KELAUTAN DAN PERIKANAN REPUBLIK INDONESIA NOMOR 47/KEPMEN-KP/2016 [online] available at http://jdih.kkp.go.id/peraturan/47-kepmen-kp2016-ttg-estimasi-potensi...sdi.....pdf (accessed 28 September 2018)

MUSTAQBAL.M.S.,ROERI.F.F, HENDRA.R.,2015. Pengujian Aplikasi Menggunakan Black Box Testing Boundary Value Analysis(Studi Kasus : Aplikasi Prediksi Kelulusan Snmptn. Jurnal Ilmiah Teknologi Informasi Terapan. Vol.1,No.3: 31-36.

NUR HIDAYATI,2018. Penggunaan Rapid Application Development Dalam Rancang Bangun Program Simpan Pinjam Pada Koperasi. Jurnal Ilmiah Penelitian dan Penerapan Teknologi Sistem Informasi 87.Vol.2,No.2 : 167:171.

OMAR.P,ASTRIANA.M,MIFTAHUL.K.,2018. Sistem Informasi Inventori Barang Menggunakan Metode Object Oriented Di Pt. Livaza Teknologi Indonesia Jakarta. Jurnal PROSISKO. Vol5,No.1: 27-35.

SULYANA.E.D,SAFRUDDIN,

ZAINUDDIN.M.,2016. Aplikasi Hypertext Markup Language Untuk Mendesain Sistem Informasi Perikanan Teri (Stolephorus Spp) Di Teluk Bone. Jurnal IPTEKS PSP, Vol.3, No.6: $501-509$.

VICTOR MARUDUT MULIA SIREGAR. 2018. Perancangan Sistem Informasi Inventaris Barang Pada Sekolah Sma Negeri 4 Pematangsiantar. IT Journal Research and Development.Vol. 3,No.1:54-61. 
YUNI SUGIARTI, 2013, Analisis dan Perancangan UML( Unified Modeling Language) Generated VB.6, Graha Ilmu Yogyakarta

\section{PROFIL PENULIS}

Lidya Elsye Reniban. Tahun 2007 Lulus S1 Fakultas
Teknologi Industri, Jurusan Teknik Informatika Universitas Gunadarma. Sekarang sedang menempuh pendidikan Strata-2 Manajemen Sistem Informasi sejak tahun 2017, Universitas Gunadarma. 